\title{
Transgenic Lettuce Seedlings Carrying Hepatitis B Virus Antigen HBsAg
}

\author{
Jackson Marcondes ${ }^{1}$ and Ekkehard Hansen ${ }^{2}$ \\ ${ }^{1}$ Biochemical Laboratory of Plants and Microorganisms, School of Agricultural Sciences and Veterinary, UNESP; Jaboticabal, SP; ${ }^{2}$ Laboratory \\ of Biotechnology, State University of North Fluminense; Campos dos Goytacazes, RJ, Brazil
}

\begin{abstract}
The obtainment of transgenic edible plants carrying recombinant antigens is a desired issue in search for economic alternatives viewing vaccine production. Here we report a strategy for genetic transformation of lettuce plants (Lactuca sativa L.) using the surface antigen HBsAg of hepatitis B virus. Transgenic lettuce seedlings were obtained through the application of a regulated balance of plant growth regulators. Genetic transformation process was acquired by cocultivation of cotyledons with Agrobacterium tumefaciens harboring the recombinant plasmid. It is the first description of a lettuce Brazilian variety "Vitória de Verão" genetically modified.

Key-Words: Edible vaccine, hepatitis B, oral immunization, recombinant antigen, transgenic plants.
\end{abstract}

Brazilian National Immunization Program presents a good schedule viewing hepatitis B immunization for infants, adolescents, and adults. However, in 2006 were confirmed 14,761 cases of hepatitis B in the country. There are about 350 million hepatitis B virus (HBV) carriers in worldwide and these chronic carriers are responsible for one to five percent of infection spreading [1]. These data relate the need of amplified programs of immunization and the development of new vaccines.

Together with medical, epidemiological, ethical, and practical considerations, economic considerations are also taken into account in the allocation process of health care resources. In addition, the advent of cheaper HBV vaccines has fortified the argument for universal HB vaccination strategies. Vaccines with higher immunogenicity and that are easier to deliver are desirable and this issue is leading several interesting approaches to develop potential vaccines. Since 1987 two recombinant vaccines produced into Saccharomices cerevisiae cells by Sharp \& Dhome and Smith Kline Beechmam have been utilized for HBV immunization. However, one of the factors that make it difficult and raise the price of production in every system consists in the purification process of the recombinant antigen.

HBsAg was the first viral antigen chosen to be produced in transgenic plants, firstly in tobacco [3] and subsequently in lupin callus and lettuce adapted to colder climates [4]. HBsAg is the abundantly expressed envelope protein as a dimmer of two identical polypeptides encoded by the same gene. Usually one of the polypeptides is glycosylated and the formation of the dimmer is essential for antigenecity and immunogenecity [5]. Thus, striking improvements in recombinant antigen were achieved by alternative polyadenylation signals and fusion proteins containing targeting signals designed to enhance integration or retention of HBsAg in the endoplasmic reticulum (ER) of plant cells [6].

Received on 12 July 2008; revised 10 November 2008.

Address for correspondence: Dr. Jackson Marcondes. Departamento de Tecnologia, UNESP, Via de acesso Paulo Donato Castellane, s/n. Zip code: Code: 14884-900, Jaboticabal, SP, Brazil - Phone/Fax: +55 [16] 32092675. E-mail: jackson@fcav.unesp.br.

The Brazilian Journal of Infectious Diseases 2008;12(6):469-471. (C) 2008 by The Brazilian Journal of Infectious Diseases and Contexto Publishing. All rights reserved.
This led us to construct recombinant DNA plasmids containing the encoding sequence of HBsAg and the same construction fused with the SEQDEL sequence responsible for ER sorting. After, we attempt to obtain transgenic lettuce plants adapted to tropical climate using variety "Vitória de Verão".

\section{Obtainment of Transgenic Plants}

HBsAg coding region with an introduced BamHI site was created by Kawashima et al. [7] applying PCR with the "S" fragment of $\mathrm{HBV}$ as template. Recombinant HBsAg was cloned into plasmid pRT $/$ Not/Asc and the recombinant gene was subsequently introduced into the binary vector pGPTV/KAN/ Asc [8] generating the plasmid pG35SHBsAg (Figure 1). The same process was performed in order to acquire the plasmid pG35SHBsAg[ER], while in this case the antisense primer account with the SEKDEL extension based on the nucleotides $<$ TAGCTCATCTTTCTCAGA> (Figure 1). Recombinant constructs were analyzed by DNA sequencing and showed the correspondent identity to the cloned fragment from "S" DNA sequence from $\mathrm{HBV}$ genome.

After seven days of germination, roots, hypocotyls, and cotyledons of lettuce (Lactuca sativa L.) variety "Vitória de Verão" were cut and cocultivated with recombinant Agrobacterium tumefaciens $\mathrm{C} 58 \mathrm{C} 1 \mathrm{Rif}^{\mathrm{R}}$ containing pG35SHBsAg or pG35SHBsAg[ER]. The cocultivation was carried out in $20 \mathrm{~mL}$ of liquid MS (Murashige-Skoog medium) and $400 \mu \mathrm{L}$ of a 48 hour liquid culture of A. tumefaciens. Subsequently, the lettuce tissue was transferred to Petri dishes containing solid MS supplemented by growth regulators Indole3-acetic Acid (IAA - 3 mg/L) and Kinetin ( $0.02 \mathrm{mg} / \mathrm{L}$ ) for callus induction, the antibiotic kanamycin $(100 \mathrm{mg} / \mathrm{L})$ for selection of transformed tissue, and the antibiotic cefotaxin $(250 \mathrm{mg} / \mathrm{L})$ to eliminate the bacteria. Plants were regenerated on MS using 0.2 $\mathrm{mg} / \mathrm{L}$ of IAA and $0.2 \mathrm{mg} / \mathrm{L}$ of kinetin. The plant tissue was kept at $22^{\circ} \mathrm{C}-26^{\circ} \mathrm{C}$ under a 16 hours light $/ 8$ hours dark cycle. Transgenes were analyzed by PCR amplification of the introduced HBsAg or nptII coding sequences and agarose gel electrophoresis.

\section{Discussion}

Oral immunization based on transgenic edible plants as dietary vaccines, i.e. the use of transgenic plants as a new 
Figure 1. Plasmid constructs pG35SHBsAg and pG35SHBsAg[ER]. HBsAg/HBsAgER: coding sequence of HBsAg antigen and fusion with endoplasmatic reticulum sorting sequence $<$ SEQDEL $>$; R/L: right and left borders of T-DNA necessary for DNA transference by A. tumefaciens; uidA: bacterial $\beta$-glucuronidase coding sequence; P35S: promoter 35S from cauliflower mosaic virus; $\Omega$ : leader sequence from tobacco mosaic virus; Pnos: promoter from A. tumefaciens nopaline synthase gene; $n p t I I$ : coding sequence of neomycin phosphotransferase that confers resistance to the antibiotic kanamycin; T: transcription termination sequence.

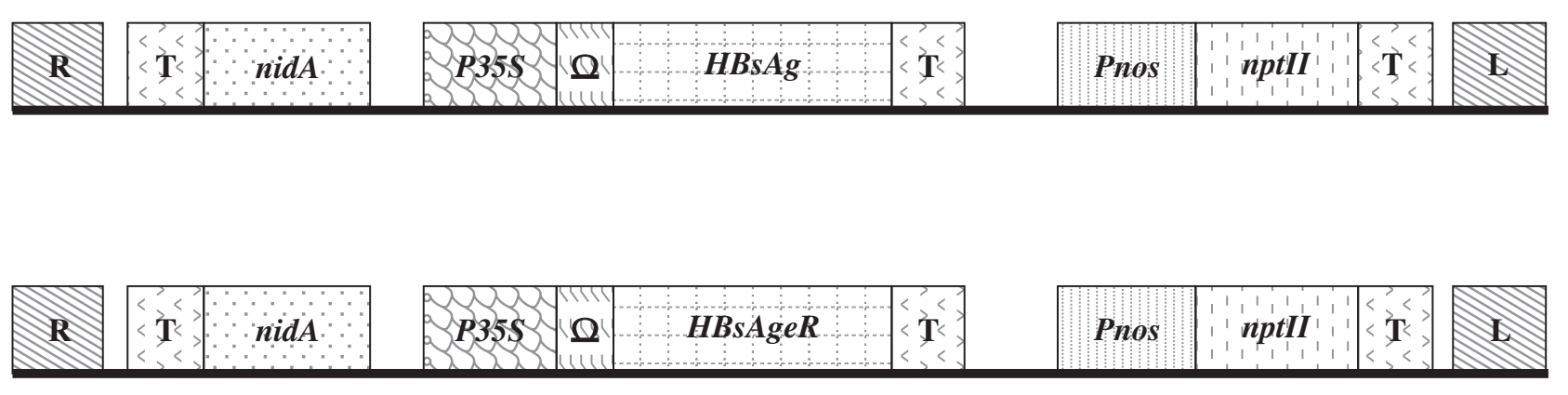

Figure 2. Transgenic lettuce callus and regenerated seedlings. A) Callus formation on the edge of cotyledons with 30 days after inoculation with A. tumefaciens harboring the recombinant plasmid pG35SHBsAg; B) Brown callus in IAA (3 mg/L) and Kinetin $(0.02 \mathrm{mg} / \mathrm{L})$ supplemented culture medium with 45 days; C) Green callus and shoot formation in IAA (0.2 mg/L) and kinetin $(0.2$ $\mathrm{mg} / \mathrm{L})$ supplemented culture medium with 45 days; D) Seedling in IAA $(0.2 \mathrm{mg} / \mathrm{L})$ and kinetin $(0.2 \mathrm{mg} / \mathrm{L})$ supplemented medium with 60 days. Bar: $0,5 \mathrm{~cm}(\mathrm{~A})$ and $1,0 \mathrm{~cm}$ (B, C, and D).
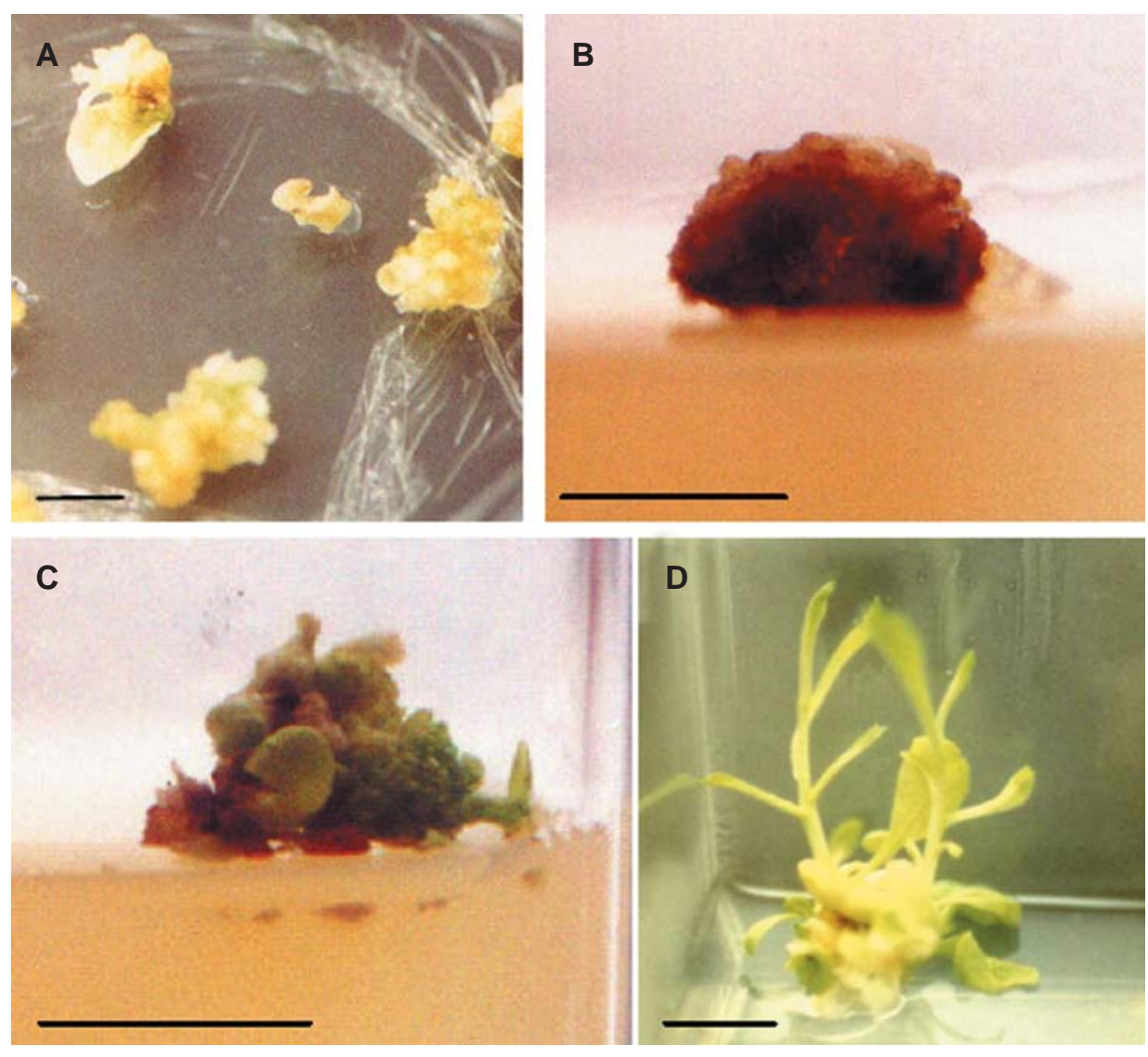
Figure 3. PCR amplification of the transgenes in transgenic callus and regenerated seedlings tissues. A) HBsAg coding sequence resulting in a 681 bp fragment; B) nptII coding sequence resulting in a 477 bp fragment. M: Molecular weight marker 250 bp DNA ladder PROMEGA (2 $\mu \mathrm{g})$; C-: negative control; C+: positive control.

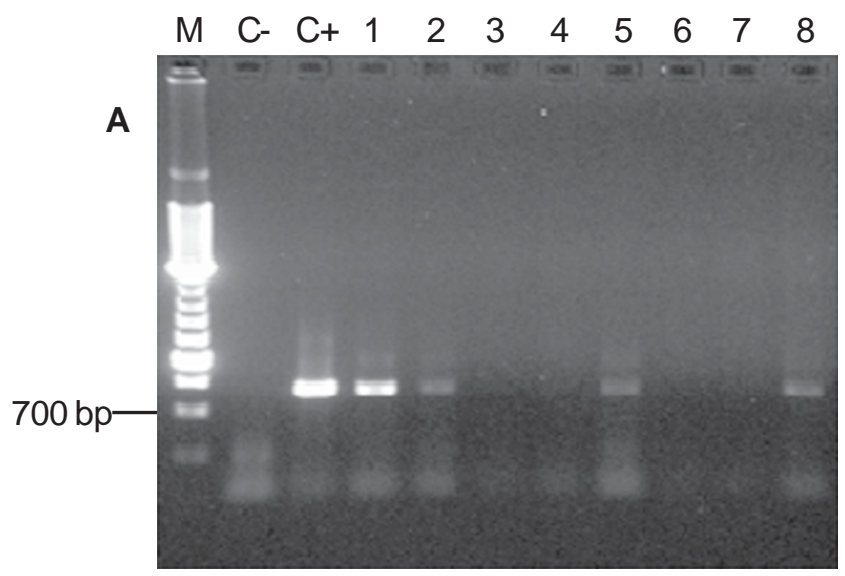

vaccine source for a new vaccination strategy, will focus on the unique properties of the mucosal immune systems. It can successfully induce the antigen-specific sIgA-mediated local immune response as well systemic immunity. Further, oral routes of vaccination are feasible and acceptable.

Genetic transformation of plants is the most recent approach that has been applied in order to produce biopharmaceuticals and immunoprophylactis in transgenic plants [9]. Edible plant vaccines are still more attractive for scientific and commercial purposes [2]. The costs of production and distribution could be severely reduced spreading this kind of vaccine to poor countries. Antigens stored in plant cells would be stable against temperature changes, making it possible to overcome the need for cold storage. Further, the administration of the edible plant vaccine could be more easily acquired once it would not require the use of disposable needles or other specialized equipment and staff.

Among three different explants, roots, hypocotyls and cotyledons, the later was the less recalcitrant to A. tumefaciens infection and to genetic plant transformation and regeneration. IAA is the primary auxin in plants and its exogenous combination with kinetin is responsible by induction of other endogenous growth regulators, as ethylene, and several synergistic effects, beside their morphological roles. Beyond the stimulatory effect on cell division, the mixture of auxin and kinetin induces the beginning of cell differentiation [10].

When cotyledons cocultivated with A. tumefaciens harboring recombinant plasmid were placed directly in the equal combination of growth regulators the regeneration effect was superior. The combination of $0.2 \mathrm{mg} / \mathrm{L}$ of IAA and $0.2 \mathrm{mg} /$ $\mathrm{L}$ of kinetin was much more efficient in the seedlings regeneration presenting a well developed aerial part (Figure 2 ). In the first 15 days in culture tissue, a mass of callus surrounding the growing seedling was observed. The callus already presented a greenery aspect. This mass excess was cut away from seedlings to facilitate the regeneration process that completed after 21 days in culture tissue. More than one regenerated shoot was observed by explants (Figure 2).

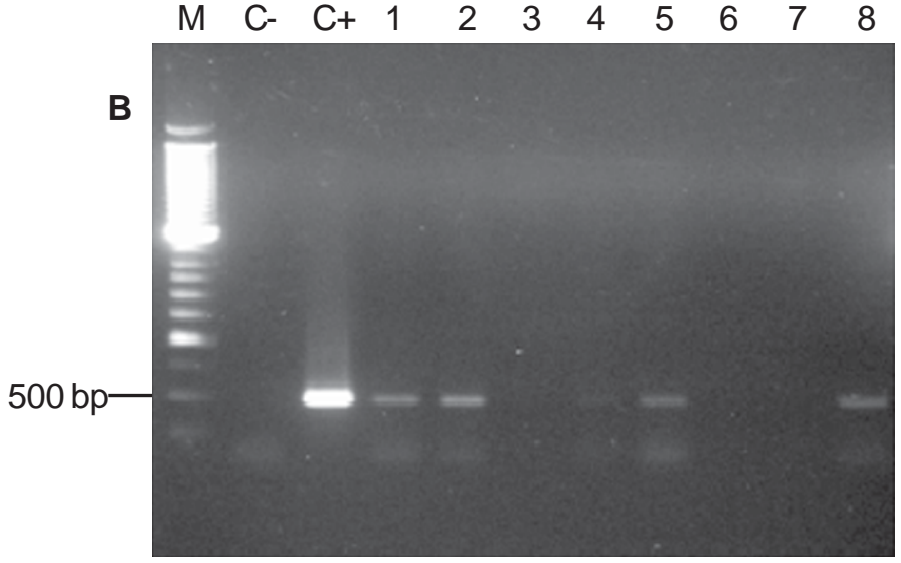

At the moment, only the construct in recombinant plasmid pG35SHBsAg was subjected to transformation and regeneration. Regenerated shoots were analyzed for the presence of the transgenic neomycin phosphotransferase (nptII) and HBsAg by PCR amplification. The presence of the transgenes was confirmed in regenerated shoots (Figure 3). Validation of transgenic plants in genetic transformation experiments was effected through the amplification of a 681 bp HBsAg and a 477 bp nptII fragments.

Our results had shown the success obtaining of recombinant HBsAg gene in transgenic tissue of lettuce variety "Vitória de Verão", a variety adapted to high temperatures in tropical regions. Regeneration of transgenic fertile plants and expression in leaf tissue may lead to production of a cheaper vaccine locally where it is needed.

\section{References}

1. Hou J., Liu Z., Gu F. Epidemiology and prevention of hepatitis B virus infection. Int J Med Sci 2005;2:50-7.

2. Streatfield S.J., Jilka J.M., Hood E.E., et al. Plant-based vaccines: unique advantages. Vaccine 2001;19:2742-8.

3. Mason H.S., Lam D.M., Arntzen C.J. Expression of hepatitis B surface antigen in transgenic plants. Proc Natl Acad Sci USA 1992;89:11745-9.

4. Kapusta J., Modelska A., Figlerowicz M., et al. A plant-derived edible vaccine against hepatitis B virus. FASEB J 1999;13:1796-9.

5. Purcell R.H. Hepatites Viruses: Changing patterns of human disease. Proc Natl Acad Sci USA 1994;91:2401-6.

6. Richter L.J., Thanavala Y., Arntzen D.J., Mason H.S. Production of hepatitis B surface antigen in transgenic plants for oral immunization. Nat Biotechnol 2000;18:1167-71.

7. Kawashima C.G., Babá E.H., Hansen E. Expression of recombinant hepatitis B virus antigen HBsAg in transgenic plant callus. Protein and Peptide Letters 2001;8:97-123.

8. Überlacker B., Werr W. Vectors with rare-cutter restriction enzyme sites $\mathrm{f} 1$ or expression of open reading frames in transgenic plants. Molecular Breeding 1996;2:293-5.

9. Hansen E., Kawashima C.G. Delivery of immunoprophylactics in transgenic plants. BioDrugs 2000;13:381-90.

10. Pink D.A.C., Carter P.P.J. Propagation of lettuce (Lactuca sativa) breeding material by tissue culture. Ann Appl Biol 1987;110:611-6. 